\title{
Allelopathic Effects of Aqueous Extracts of Alternanthera philoxeroides on the Growth of Zoysia matrella
}

\author{
Yongjie Huang ${ }^{1 *}$, Yanyan $\mathrm{Ge}^{1}$, Qingling Wang' ${ }^{2}$ Hui Zhou ${ }^{1}$, \\ Wuxing Liu' ${ }^{2}$ Peter Christie ${ }^{2}$ \\ ${ }^{1}$ Collaborative Innovation Center of Recovery and Reconstruction of Degraded Ecosystems in Wanjiang City Belt, \\ Anhui Province; College of Life Sciences, Anhui Normal University, Wuhu 241000, China \\ ${ }^{2}$ Key Laboratory of Soil Environment and Pollution Remediation, Institute of Soil Science, \\ Chinese Academy of Sciences, Nanjing 210008, China
}

Received: 11 July 2016

Accepted: 4 September 2016

\begin{abstract}
Alternanthera philoxeroides is a perennial invasive species worldwide which can greatly affect native ecosystems and agricultural production. Our research studied the allelopathic effects of aqueous extracts of A. philoxeroides on the growth and antioxidant enzyme activities of Zoysia matrella, and isolated and analyzed the dominant allelochemicals in root extracts of $A$. philoxeroides. The overall allelopathic effects of $A$. philoxeroides extracts on the growth and antioxidant enzyme activities of Z. matrella were found to be slightly stimulatory (concentrations $\left.\leq 10 \mathrm{~g} \mathrm{~L}^{-1}\right)$ and highly inhibitory $\left(\geq 40 \mathrm{~g} \mathrm{~L}^{-1}\right)$. Malondialdehyde contents were significantly enhanced with increasing concentrations of $A$. philoxeroides extracts. The strength of the allelopathic effects of three extracts of $A$. philoxeroides on $Z$. matrella followed the order: roots $>$ leaves $>$ stems. The dominant substance was extracted and identified to be ethyl propionate by gas chromatographymass spectrometry (GC-MS). Pot experiment results show that the effects of ethyl propionate on growth and enzyme activities of $Z$. matrella also ranged from slightly stimulating to highly inhibiting in a similar fashion to the effects of $A$. philoxeroide extracts on Z. matrella. The overall allelopathic effects of $A$. philoxeroides on $Z$. matrella ranged from slightly stimulating to highly inhibiting. The most abundant allelochemical component of root extracts was identified as ethyl propionate, which also exhibited inhibitory effects similar to A. philoxeroides extracts on Z. matrella.
\end{abstract}

Keywords: allelopathic effects, Alternanthera philoxeroides, biological invasions, ethyl propionate, Zoysia matrella

*e-mail: yongjiehuang0108@163.com 


\section{Introduction}

Biological invasion refers to the invasion of new environments by alien species from their original habitats through natural or artificial processes and resultant damage to the native ecosystem [1]. Biological invasions can severely affect indigenous biological diversity, natural resources [2], and even global ecosystem balance [3-4], as the invasive species are often more competitive than the native species. Alternanthera philoxeroides, a perennial invasive aquatic plant, can rapidly outcompete indigenous species and occupy their aquatic or terrestrial niche to become the dominant species [5]. The country of origin of $A$. philoxeroides is Brazil. It was introduced into Shanghai as forage in the 1930s and is now widely distributed in over 20 provinces in China, where it has grown over a total land area of $>800,000$ ha. A. philoxeroides has been suggested to be one of the 20 most dangerous invasive alien species in China [6]. The native ecosystem can be irreversibly damaged after invasion, and agricultural production can be greatly affected [7].

Numerous studies indicate that biological invasions are affected by several factors such as allelopathic characteristics, adaptability and resilience of environments to invasion, and interference from human activities. Allelopathy has been considered to play a vital role in successful invasions by alien species [8-9]. Certain plant species secrete allelochemicals, which exert positive or negative effects on neighboring plants or microorganisms in the environment [10]. The allelochemical isolated from Ficus microcarpa inhibits the growth of Chlorella pyrenoidosa and the primary active fraction was identified as 2-propyl phenol [11]. The allelochemical extracts of invasive plants may inhibit the seed germination and seedling growth of acceptor plants and also exert effects on their antioxidant enzyme activities and malondialdehyde (MDA) contents [12-14].

Invasive species exert negative impacts on environmental, economic, and social systems worldwide [15-16]. Previous studies on A. philoxeroides have focused mainly on its biological characteristics and its apparent impacts on the surrounding environment and biological control in agricultural and aquatic ecosystems [17-18]. The allelopathic effects of $A$. philoxeroides on turfgrass growth and the allelochemical components of $A$. philoxeroides remain to be studied. In our previous field investigations we found that invasion by A. philoxeroides' negatively impacted agricultural ecosystems and also the revegetation of urban landscapes. Zoysia matrella lawns exhibited retarded growth and lower plant densities in zones invaded by $A$. philoxeroides.

Understanding the mechanisms involved in the success of the invasion is crucial to efforts to reduce negative impacts. The aims of the present study were therefore to study how the allelochemicals of $A$. philoxeroides influence $Z$. matrella and its enzyme activities, analyze the allelochemicals present in root extracts of $A$. philoxeroides by GC-MS, and identify the dominant allelochemical compound(s) responsible for the allelopathic activity of this invasive species.

\section{Materials and Methods}

\author{
Plant Materials and Preparation \\ of Extracts
}

A. philoxeroide individuals were collected from Wuhu City, Anhui province, in eastern China (313'스, $118^{\circ} 36^{\prime} \mathrm{E}$ ). They were separated into different parts (roots, stems, and leaves) which were dried and ground. An aliquot of $8 \mathrm{~g}$ of each plant part was mixed with de-ionized water $(1 \mathrm{~L})$ at a ratio of 1:25 (w/v). The turbid solutions were placed on a shaker $\left(250 \mathrm{rpm}, 25^{\circ} \mathrm{C}\right)$ for $24 \mathrm{~h}$ and the extracts were filtered by vacuum through qualitative filter paper using a Büchner funnel. Aliquots of $80 \mathrm{~g} \mathrm{~L}^{-1}$ aqueous filtered extracts were diluted with distilled water to give concentrations of 5,10,20,40, and $80 \mathrm{~g} \mathrm{~L}^{-1}$ and stored at $4^{\circ} \mathrm{C}$ until being used in a pot experiment.

\section{Pot Experiment}

Z. matrella seedlings were purchased from Qingshui in Wuhu County and were planted at the laboratory of Anhui Normal University by selecting 100 uniform branch seedlings and transplanting them into plastic pots (30 cm diameter $\times 15 \mathrm{~cm}$ height) with $2 \mathrm{~kg}$ soil for three weeks. An aliquot of $50 \mathrm{ml}$ of the extracts of different plant parts (roots, stems, and leaves) of $A$. philoxeroides (concentrations 5, 10, 20, 40, and $80 \mathrm{~g} \mathrm{~L}^{-1}$ ) were added to pots every five days for a total of 30 days. Deionized water was added to pots as the control. There were 16 treatments and three replicates of each treatment. The pots were arranged in a completely randomized design and the position of each pot was re-randomized every week. About 50-100 mL deionized water was added to each pot every three days according to evaporation, and the soil was regularly adjusted to $20 \%(\mathrm{w} / \mathrm{w})$ moisture content during the experiment.

\section{Effects of Extracts on the Biomass and Enzyme Activities of $Z$. matrella}

Plant and soil samples were collected after 30 days. The plants were washed with de-ionized water and plant height $(\mathrm{cm})$, fresh weight $(\mathrm{g})$, and the fresh weights of roots and shoots were determined. All samples were stored at $4^{\circ} \mathrm{C}$.

The enzymatic antioxidants of $Z$. matrella were tested by placing the leaf samples $(0.2 \mathrm{~g})$ in $2 \mathrm{~mL}$ of $50 \mathrm{mmol}$ phosphate buffer ( $\mathrm{pH} 7.8$ ). The supernatant was stored in centrifuge tubes for further assay after centrifuging.

We determined superoxide dismutase (EC: 1.15.1.1) activity using NBT-illumination [19]. The reaction mixture (3 mL) was composed of $1.5 \mathrm{~mL}$ phosphate buffer $(\mathrm{pH}$ 7.8), $80 \mathrm{mg}$ methionine (Met), $4 \mathrm{mg}$ nitroblue tetrazolium (NBT), $4 \mathrm{mg} \mathrm{Na} \mathrm{NDDTA}_{2} 0.4 \mathrm{mg}$ riboflavin, and $0.1 \mathrm{~mL}$ supernatant (i.e., enzyme extract from Z. matrella), and 
$0.8 \mathrm{~mL}$ distilled water. The reaction mixtures were exposed to light (4,000 lux irradiance) for 20 minutes. A complete reaction mixture without enzyme served as the control and a reaction mixture kept in the dark served as a blank. The absorbance was measured at $560 \mathrm{~nm}$ and one unit of SOD was defined as the quantity of enzyme resulting in 50\% inhibition of the photochemical reduction of NBT and was expressed as $\mathrm{U} \mathrm{g}^{-1}$.

Catalase (EC: 1.11.1.6) activity was estimated by homogenizing $0.5 \mathrm{~g}$ of plant samples in $5 \mathrm{~mL}$ extraction solution containing $50 \mathrm{mmol}$ phosphate buffer $(\mathrm{pH}$ 7.0) and dithiothreitol. The absorbance was measured at $240 \mathrm{~nm}$ and one unit of CAT was defined as the production of dioxygen from hydrogen peroxide $(1 \%)$ in $50 \mathrm{mmol}$ phosphate buffer in $1 \mathrm{~min}$ and expressed as $\mathrm{U} \mathrm{g}^{-1} \min ^{-1}[20]$.

The malondialdehyde (MDA - a product of membrane lipid peroxidation) content of the plant samples was determined using the thiobarbituric acid method [21]. The reaction mixture was composed of $0.2 \mathrm{~g}$ of plant sample, $5 \mathrm{~mL}$ phosphate buffer ( $\mathrm{pH} 7.0), 3 \mathrm{~mL}$ of $0.1 \%(\mathrm{w} / \mathrm{v})$ trichloroacetic acid (TCA), and $3 \mathrm{~mL}$ of $0.5 \%$ $(\mathrm{w} / \mathrm{v})$ thiobarbituric acid (TBA). The reaction mixture was cooled quickly after incubation in boiling water $\left(100^{\circ} \mathrm{C}\right.$, $30 \mathrm{~min})$. The tubes were centrifuged at $12,000 \mathrm{rpm}$ for $30 \mathrm{~min}$ and the absorbance of the supernatant was read at $532 \mathrm{~nm}$ and measured at $600 \mathrm{~nm}$ to reduce the nonspecific absorption value. The MDA concentration was calculated by using an extinction coefficient of $155 \mathrm{mM}^{-1} \mathrm{~cm}^{-1}$ and expressed as $\mu \mathrm{g} \mathrm{g}^{-1}$.

\section{The Response Index (RI) and Synthetic Allelopathic Index (SE)}

Root length, plant height, fresh weight, MDA content, and enzyme activities (SOD, CAT) as well as the allelopathic effect index (Response Index) were determined and recorded. The Response Index (RI) of allelopathy was calculated using the formula described by Williamson and Richardson [22] as follows:

$$
\begin{aligned}
& \mathrm{RI}=1-\mathrm{C} / \mathrm{T}(\mathrm{T} \geq \mathrm{C}) \\
& \mathrm{RI}=\mathrm{T} / \mathrm{C}-1(\mathrm{~T}<\mathrm{C})
\end{aligned}
$$

In the model, $\mathrm{C}$ is the control response (root length, plant height, fresh weight, MDA content, and enzyme activities; SOD, CAT) in the control, i.e., $0 \mathrm{~g} \mathrm{~L}^{-1}$ A. philoxeroides extract (roots, stems, and leaves), $\mathrm{T}$ is the treatment response (root length, plant height, fresh weights, MDA content, and enzyme activities; SOD, CAT) following treatment with plant extracts. When RI $>0$ the effect is stimulatory and when RI $<0$ the effect is inhibitiory. The synthetic allelopathic index (SE) was calculated as the average of RI $(-1<\mathrm{RI}<1)$ [23]. A positive value $(+)$ indicates stimulation by the treatment and a negative value (-) indicates inhibition by the treatment (with zero indicating no significant difference from the control) [24].

\section{Analysis of the Compounds Extracted from A. philoxeroides}

Aliquots $(50 \mathrm{~mL})$ of $A$. philoxeroides root extracts were transferred to a Soxhlet apparatus. The solution was extracted with $50 \mathrm{~mL}$ of ethyl acetate at a ratio of $1: 1(\mathrm{v} / \mathrm{v})$. Then the extract was concentrated to a final volume of $1 \mathrm{~mL}$ using a rotary evaporator at $55^{\circ} \mathrm{C}$ and the samples were immediately analyzed by GC-MS using an Agilent 6890 GC-5973 MSD (Agilent Technologies, Santa Clara, CA) fitted with an RTX-5 ms capillary column (Restek Corporation, Bellefonte, PA), $30 \mathrm{~m} \times 0.25 \mathrm{~mm}$ i.d., $0.25 \mu \mathrm{m}$. The optimized conditions for the analysis of the root aqueous extracts using the column configuration were as follows: helium was used as the carrier gas at a flow rate of $1.5 \mathrm{~mL} \mathrm{~min}^{-1}$; the injection temperature was $260^{\circ} \mathrm{C}$, injection volume $1 \mu \mathrm{L}$ and operated in split mode (1:100); the temperature program was $40^{\circ} \mathrm{C}$ (held for $2 \mathrm{~min}$ ) to

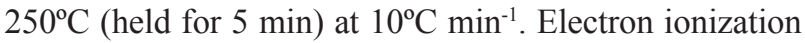
for the mass spectrometry detection experiments used temperatures of 200 and $250^{\circ} \mathrm{C}$ for the ion source and interface, respectively. The scan range of the mass-tocharge ratio $(\mathrm{m} / \mathrm{z})$ of ions was $40-700$, the scanning interval was $0.5 \mathrm{~s}$, and the scan rate $1.5 \mathrm{scans} \mathrm{s}^{-1}$. Compounds were tentatively identified $(p<0.05)$ on the basis of the National Institute of Standards and Technology (NIST) Mass Spectral Library.

\section{Effects of Ethyl Propionate on the Biomass and Enzyme Activities of $Z$. matrella}

Ethyl propionate was found to be the most abundant compound in the root extracts of A. philoxeroides. An aliquot of $100 \mu \mathrm{L}$ ethyl propionate was mixed with $1 \mathrm{~mL}$ distilled water and incubated for $10 \mathrm{~min}$ in the laboratory at ambient temperature. The mixed solution of ethyl propionate was added to the pots once every 5 days for a total of 30 days, and the final concentrations of the extracts were $0.05,0.1,0.5,1,5$, and 10 mmol. Pots treated with distilled water were used as controls. Selected (100 branch) Z. matrella seedlings were transplanted into plastic pots. Root length, plant height and fresh weights of the shoots, the activities of superoxide dismutase (SOD), and catalase (CAT) and malondialdehyde (MDA) contents of Z. matrella were determined as described above. All treatments were conducted in triplicate.

\section{Statistical Analysis}

Student's theoretical criterion was the basis of the confidence intervals of the estimates and standard deviation (SD) was calculated at $p<0.05$. Correlation coefficient between different treatments and Z. matrella biomass were calculated in order to evaluate their interaction. Significant differences among the means were determined using Duncan's multiple range test at $p<0.05$. The results of allelopathic effects were statistically evaluated using the SPSS 19.0 statistical package. The MDA content and 
Table 1. Effects of different concentrations of the extracts of $A$. philoxeroides plant parts (roots, leaves, and stems) on the fresh biomass of $Z$. matrella.

\begin{tabular}{|c|c|c|c|c|}
\hline Treatment & $\begin{array}{c}\text { Concentration } \\
\left(\mathrm{g} \mathrm{L}^{-1}\right)\end{array}$ & $\begin{array}{l}\text { Root length } \\
\qquad(\mathrm{cm})\end{array}$ & $\begin{array}{l}\text { Plant height } \\
\text { (cm) }\end{array}$ & $\begin{array}{c}\text { Fresh weight } \\
\text { (g) }\end{array}$ \\
\hline Control & 0 & $4.48 \pm 0.76 \mathrm{a}$ & $17.3 \pm 1.66 \mathrm{~b}$ & $0.62 \pm 0.05 \mathrm{ab}$ \\
\hline \multirow{5}{*}{ Root extract } & 5 & $5.27 \pm 1.10 \mathrm{a}$ & $16.82 \pm 0.47 b$ & $0.67 \pm 0.13 \mathrm{a}$ \\
\hline & 10 & $3.87 \pm 0.83 \mathrm{ab}$ & $19.75 \pm 1.38 \mathrm{a}$ & $0.77 \pm 0.10 \mathrm{a}$ \\
\hline & 20 & $2.68 \pm 1.03 b c$ & $14.08 \pm 1.08 \mathrm{c}$ & $0.5 \pm 0.07 b c$ \\
\hline & 40 & $2.7 \pm 0.58 \mathrm{bc}$ & $13.02 \pm 1.84 \mathrm{c}$ & $0.41 \pm 0.09 \mathrm{~cd}$ \\
\hline & 80 & $2.03 \pm 0.73 \mathrm{c}$ & $11.9 \pm 0.97 \mathrm{c}$ & $0.34 \pm 0.05 \mathrm{~d}$ \\
\hline \multirow{5}{*}{ Stem extract } & 5 & $4.68 \pm 0.59 \mathrm{ab}$ & $21.02 \pm 3.21 \mathrm{a}$ & $0.81 \pm 0.10 \mathrm{a}$ \\
\hline & 10 & $5.78 \pm 1.05 \mathrm{a}$ & $18.44 \pm 2.29 \mathrm{ab}$ & $0.73 \pm 0.08 \mathrm{ab}$ \\
\hline & 20 & $4.94 \pm 0.89 \mathrm{ab}$ & $19.08 \pm 2.08 \mathrm{ab}$ & $0.72 \pm 0.03 \mathrm{ab}$ \\
\hline & 40 & $4.24 \pm 0.55 b$ & $17.41 \pm 1.93 \mathrm{ab}$ & $0.68 \pm 0.07 \mathrm{ab}$ \\
\hline & 80 & $3.62 \pm 0.73 b$ & $15.07 \pm 1.35 \mathrm{~b}$ & $0.48 \pm 0.11 \mathrm{c}$ \\
\hline \multirow{5}{*}{ Leaf extract } & 5 & $5.19 \pm 1.46 \mathrm{a}$ & $18.6 \pm 1.10 \mathrm{a}$ & $0.79 \pm 0.07 \mathrm{a}$ \\
\hline & 10 & $4.66 \pm 0.57 \mathrm{a}$ & $17.39 \pm 1.90 \mathrm{ab}$ & $0.73 \pm 0.11 \mathrm{ab}$ \\
\hline & 20 & $3.52 \pm 0.63 \mathrm{ab}$ & $16.24 \pm 1.49 \mathrm{abc}$ & $0.68 \pm 0.05 \mathrm{ab}$ \\
\hline & 40 & $2.61 \pm 1.01 \mathrm{~b}$ & $15.7 \pm 0.60 \mathrm{bc}$ & $0.5 \pm 0.07 \mathrm{c}$ \\
\hline & 80 & $2.59 \pm 0.40 \mathrm{~b}$ & $13.82 \pm 1.23 \mathrm{c}$ & $0.43 \pm 0.05 \mathrm{c}$ \\
\hline
\end{tabular}

The data are the mean values $(\mathrm{n}=3) \pm$ standard error of the mean and different letters in the same column denote significant differences at $p<0.05$.

enzyme activities (SOD, CAT) of $Z$. matrella are presented as mean $\pm \mathrm{SD}$ of three independent analyses at the $p<0.05$ significance level.

\section{Results}

\section{Effects of the Extracts on Z. matrella Biomass}

The extracts of each plant part of $A$. philoxeroides had distinct effects on the root length, shoot height, and fresh weight of $Z$. matrella (Table 1), which increased initially (from 0 to $10 \mathrm{~g} \mathrm{~L}^{-1}$ ) and then decreased (from 10 to $80 \mathrm{~g} \mathrm{~L}^{-1}$ ) with increasing concentration of root extracts. Root length showed the largest increase (17.6\%) compared with the control when the concentration of root extracts reached $5 \mathrm{~g} \mathrm{~L}^{-1}$. In contrast, the shoot height and fresh weight increased most (14.2 and 24.2\%) when the concentration of the root extracts was $10 \mathrm{~g} \mathrm{~L}^{-1}$. Then the root length, shoot height, and fresh weight of $Z$. matrella all decreased with increasing concentrations. When the concentration of the root extracts reached $80 \mathrm{~g} \mathrm{~L}^{-1}$, the root length, shoot height and fresh weight of $Z$. matrella showed the largest decrease $(45.3,68.8$ and 54.8\%, respectively). However, the root length and plant height of Z. matrella treated with stem extracts showed no significant differences from the control and the plant fresh weight increased by $30.7 \%$ under $5 \mathrm{~g} \mathrm{~L}^{-1}$ stem extracts and then decreased with increasing stem extract concentration. The fresh weight of $Z$. matrella decreased by $22.6 \%$ compared to the control when the stem extract concentration reached $80 \mathrm{~g} \mathrm{~L}^{-1}$. Root length, shoot height, and fresh weight of Z. matrella all showed a declining trend with increasing leaf extract concentrations and decreased most at $80 \mathrm{~g} \mathrm{~L}^{-1}$ (42.2, 20.2 and $30.6 \%$, respectively).

\section{Effects of the Extracts on the MDA Content and Enzyme Activities of Z. matrella}

The MDA content of $Z$. matrella treated with root and leaf extracts usually increased with increasing concentration from 5 to $80 \mathrm{~g} \mathrm{~L}^{-1}$ of the A. philoxeroides extracts and increased most (18.8 and $33.3 \%$, respectively) at a concentration of $80 \mathrm{~g} \mathrm{~L}^{-1}$. There were no significant differences $(p<0.05)$ in MDA content when the concentration of extracts of all plant parts (roots, stems, and leaves) exceeded $40 \mathrm{~g} \mathrm{~L}^{-1}$. The MDA content of $Z$. matrella decreased significantly in the stem extract treatments at concentrations of 5 and $10 \mathrm{~g} \mathrm{~L}^{-1}$ compared to the control (Fig. 1a). The SOD and CAT activities of Z. matrella increased initially (from 0 to $20 \mathrm{~g} \mathrm{~L}^{-1}$ ) and then declined (from 20 to $80 \mathrm{~g} \mathrm{~L}^{-1}$ ) with increasing concentrations of root and leaf extracts of $A$. philoxeroides, but increased with increasing concentrations (from 5 to $80 \mathrm{~g} \mathrm{~L}^{-1}$ ) of the stem extracts of $A$. philoxeroides (Figs $1 \mathrm{~b}$, $1 \mathrm{c)}$. 

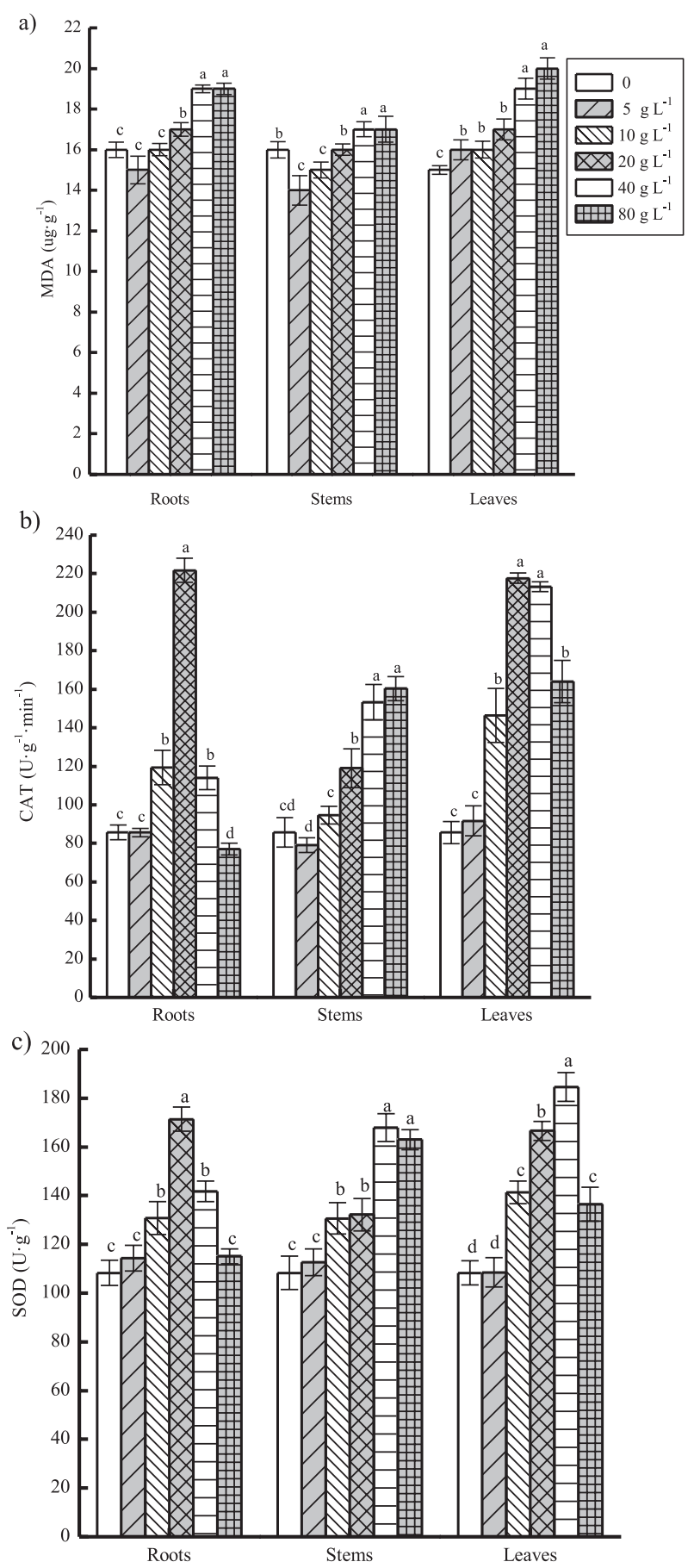

Fig. 1. MDA a), SOD b), and CAT c) activities of Z. matrella treated with different extracts of $A$. philoxeroides at concentrations of $0,5,10,20,40$, and $80 \mathrm{~g} \mathrm{~L}^{-1}$. Mean values $(\mathrm{n}=3)$ followed by the same letters are not significantly different at $p<0.05$.

\section{Response Index (RI) and Synthetic Allelopathic Index (SE)}

The response index (RI) and synthetic allelopathic index (SE) values show that the influnce of $A$. philoxeroides extracts on the root length, plant height, and fresh weight and on the antioxidant enzyme activities (CAT and SOD) of $Z$. matrella ranged from slightly stimulatory to highly inhibitory (Table 2). The RI index values $\left(\mathrm{RI}_{\mathrm{CAT}}, \mathrm{RI}_{\mathrm{SOD}}\right.$,
$\mathrm{RI}_{\mathrm{RL}}, \mathrm{RI}_{\mathrm{H}}, \mathrm{RI}_{\mathrm{FW}}$ ) of $Z$. matrella tended to increase overall initially (from 0 to $10 \mathrm{~g} \mathrm{~L}^{-1}$ ) and then decrease (from 10 to $80 \mathrm{~g} \mathrm{~L}^{-1}$ ), with the exception of $\mathrm{RI}_{\mathrm{MDA}}$, which continued to increase with increasing concentration of the extracts of the three A. philoxeroides plant parts under the conditions of the pot experiment (Table 2). The RI and SE indices were minimum when the concentration of the extracts reached $80 \mathrm{~g} \mathrm{~L}^{-1}$ in each treatment. The SE index suggests that the strength of the allelopathic effect of the three extracts was in the sequence roots $>$ leaves $>$ stems, suggesting that the roots of $A$. philoxeroides had the strongest allelopathic effect inhibiting the development of $Z$. matrella.

\section{Analysis of the Extracts of $A$. philoxeroide Roots}

The results of the analysis of root extracts of $A$. philoxeroides by GC-MS are shown in Fig. 2. According to the tandem mass spectrum identification of the major peaks, we determined the mass-to-charge ratio $(\mathrm{m} / \mathrm{z})$ of three characteristic fragmentation ions - namely 57 , 74 , and 102 . These are the characteristic fragmentation ions of ethyl propionate by reference to the NIST mass spectral database. Thus, ethyl propionate was identified as the most abundant component of the root extracts of $A$. philoxeroides (Fig. 2).

\section{Effects of Ethyl Propionate on Z. matrella Biomass}

As Table 3 shows, different concentrations of ethyl propionate amendment had different effects on plant development. The height and fresh weight of $Z$. matrella plants increased under the stress of ethyl propionate at a concentration of $0.1 \mathrm{mmol}$ and then decreased under higher concentrations. The root length of $Z$. matrella decreased overall with increasing concentrations of ethyl propionate and produced significant differences $(>1 \mathrm{mmol})$. It seems that the development of $Z$. matrella decreased the most (24.2\%) when the concentration of ethyl propionate was 5 mmol compared to the control. Additional ethyl propionate showed the strongest inhibitory effect on the root length of $Z$. matrella.

\section{Effects of Ethyl Propionate on the MDA Content and Enzyme Activities of $Z$. matrella}

The results in Table 4 show that the MDA content of Z. matrella increased continuously in a similar fashion to those treated with A. philoxeroides extracts and the MDA content increased most (84.4\%) under the stress of 10 mmol ethyl propionate compared to the control treatment. The SOD and CAT activities increased under low concentrations $(\leq 0.5 \mathrm{mmol})$ and then decreased under the higher concentrations $(\geq 1 \mathrm{mmol})$ of ethyl propionate. The SOD and CAT activities in the $10 \mathrm{mmol}$ ethyl propionate treatment decreased by 58.2 and $25.6 \%$, respectively, compared to the control (Table 4). 
Table 2. Response index (RI) and synthetical allelopathic index (SE).

\begin{tabular}{|c|c|c|c|c|c|c|c|c|}
\hline Treatment & $\begin{array}{c}\text { Concentration } \\
\left(\mathrm{g} \mathrm{L}^{-1}\right)\end{array}$ & $\mathrm{RI}_{\mathrm{CAT}}$ & $\mathrm{RI}_{\mathrm{SOD}}$ & $\mathrm{RI}_{\mathrm{MDA}}$ & $\mathrm{RI}_{\mathrm{RL}}$ & $\mathrm{RI}_{\mathrm{H}}$ & $\mathrm{RI}_{\mathrm{FW}}$ & $\mathrm{SE}$ \\
\hline \multirow{5}{*}{ Root extract } & 5 & 0.49 & 0.45 & 0.03 & 0.15 & -0.03 & 0.07 & 0.19 \\
\hline & 10 & 0.53 & 0.44 & 0.16 & -0.16 & 0.12 & 0.20 & 0.22 \\
\hline & 20 & -0.07 & 0.01 & 0.22 & -0.67 & -0.23 & -0.24 & -0.16 \\
\hline & 40 & -1.33 & -0.35 & 0.29 & -0.66 & -0.33 & -0.53 & -0.49 \\
\hline & 80 & -2.16 & -1.11 & 0.30 & -1.21 & -0.45 & -0.85 & -0.91 \\
\hline \multirow{5}{*}{ Stem extract } & 5 & 0.33 & 0.42 & -0.02 & 0.04 & 0.18 & 0.23 & 0.20 \\
\hline & 10 & 0.52 & 0.49 & 0.06 & 0.23 & 0.06 & 0.15 & 0.25 \\
\hline & 20 & 0.45 & 0.48 & 0.14 & 0.09 & 0.09 & 0.13 & 0.23 \\
\hline & 40 & 0.05 & -0.40 & 0.20 & -0.06 & 0.01 & 0.09 & -0.02 \\
\hline & 80 & -0.52 & -0.58 & 0.23 & -0.24 & -0.15 & -0.30 & -0.26 \\
\hline \multirow{5}{*}{ Leaf extract } & 5 & 0.52 & 0.49 & 0.02 & 0.14 & 0.07 & 0.21 & 0.24 \\
\hline & 10 & 0.54 & 0.50 & 0.16 & 0.04 & 0.01 & 0.15 & 0.23 \\
\hline & 20 & 0.41 & 0.18 & 0.20 & -0.27 & -0.07 & 0.08 & 0.09 \\
\hline & 40 & -0.72 & -0.41 & 0.24 & -0.71 & -0.10 & -0.25 & -0.33 \\
\hline & 80 & -1.58 & -0.67 & 0.29 & -0.73 & -0.25 & -0.44 & -0.56 \\
\hline
\end{tabular}

Positive values (+) indicate stimulation by the treatment, negative values (-) indicate inhibition, and zero is an indication of nil effect. $\mathrm{RI}_{\mathrm{RL}}$ represents the response index of root length, $\mathrm{RI}_{\mathrm{H}}$ represents the response index of height, and $\mathrm{RI}_{\mathrm{FW}}$ represents the response index of fresh weight.

\section{Discussion}

A. philoxeroides is regarded as an execrable weed that is widely distributed in tropical regions worldwide [25]. Our previous field investigation found a detrimental effect on the growth of $Z$. matrella resulting in lower plant densities in lawns and the appearance of turf degradation with invasion by $A$. philoxeroides. Allelopathy was recognized as one of the most important factors responsible

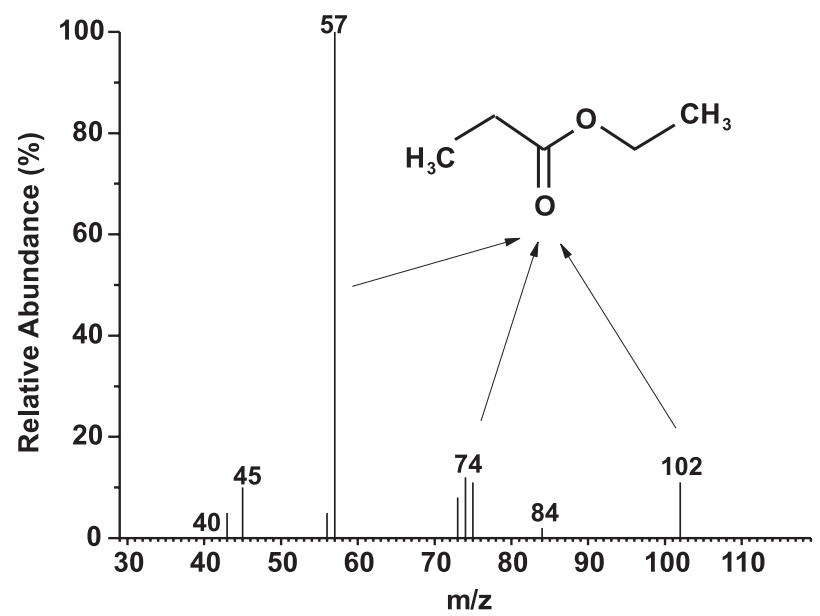

Fig. 2. Mass spectra of major peaks of extracts of $A$. philoxeroides roots. 57, 74, and $102 \mathrm{~m} / \mathrm{z}$ are the characteristic fragmentation ions of ethyl propionate. for the successful interference by alien species and the rapid occupation of the niche by ecological invaders [26]. Here, we sought to determine whether allelopathy was responsible for the invasion of $Z$. matrella by $A$. philoxeroides. In the present study it was found that the extracts of the three plant parts of $A$. philoxeroides had different influences on the growth of $Z$. matrella. Generally, low concentrations of $A$. philoxeroides extracts $\left(\leq 10 \mathrm{~g} \mathrm{~L}^{-1}\right)$ appeared to promote the growth of Z. matrella (Table 2), possibly due to the growthpromoting effects of the nutrients present in the extracts

Table 3. Effects of different concentrations of ethyl propionate on the fresh biomass of $Z$. matrella.

\begin{tabular}{|c|c|c|c|}
\hline $\begin{array}{c}\text { Concentration } \\
(\mathrm{mmol})\end{array}$ & $\begin{array}{c}\text { Root length } \\
(\mathrm{cm})\end{array}$ & $\begin{array}{c}\text { Plant height } \\
(\mathrm{cm})\end{array}$ & $\begin{array}{c}\text { Fresh } \\
\text { weight }(\mathrm{g})\end{array}$ \\
\hline 0 & $2.018 \pm 0.13 \mathrm{a}$ & $13.88 \pm 0.41 \mathrm{~b}$ & $0.6 \pm 0.05 \mathrm{ab}$ \\
\hline 0.1 & $1.94 \pm 0.28 \mathrm{ab}$ & $15.7 \pm 1.08 \mathrm{a}$ & $0.69 \pm 0.09 \mathrm{a}$ \\
\hline 0.5 & $1.63 \pm 0.38 \mathrm{ab}$ & $14.03 \pm 1.99 \mathrm{ab}$ & $0.59 \pm 0.1 \mathrm{ab}$ \\
\hline 1 & $1.6 \pm 0.1 \mathrm{~b}$ & $13.3 \pm 1.25 \mathrm{~b}$ & $0.64 \pm 0.11 \mathrm{ab}$ \\
\hline 5 & $1.53 \pm 0.25 \mathrm{~b}$ & $12.93 \pm 0.92 \mathrm{~b}$ & $0.51 \pm 0.09 \mathrm{~b}$ \\
\hline 10 & $1.66 \pm 0.15 \mathrm{~b}$ & $13.7 \pm 1.36 \mathrm{ab}$ & $0.54 \pm 0.03 \mathrm{~b}$ \\
\hline
\end{tabular}

The data are the mean values $(n=3) \pm$ standard error of the mean; different letters in the same column denote significant differences at $p<0.05$. 
Table 4. Effects of different concentrations of ethyl propionate on the MDA content and enzyme activities (SOD, CAT) of Z. matrella.

\begin{tabular}{|c|c|c|c|}
\hline $\begin{array}{c}\text { Concentration } \\
(\mathrm{mmol})\end{array}$ & $\begin{array}{c}\text { SOD } \\
\left(\mathrm{U} \cdot \mathrm{g}^{-1}\right)\end{array}$ & $\begin{array}{c}\text { CAT } \\
\left(\mathrm{U} \cdot \mathrm{g}^{-1} \cdot \mathrm{min}^{-1}\right)\end{array}$ & $\begin{array}{c}\text { MDA } \\
\left(\mathrm{ug} \cdot \mathrm{g}^{-1}\right)\end{array}$ \\
\hline 0 & $151.12 \pm 25.78 \mathrm{c}$ & $168.23 \pm 18.93 \mathrm{c}$ & $15.2 \pm 2.36 \mathrm{~b}$ \\
\hline 0.1 & $221.34 \pm 31.94 \mathrm{ab}$ & $202.16 \pm 15.28 \mathrm{ab}$ & $23.81 \pm 0.89 \mathrm{a}$ \\
\hline 0.5 & $248.09 \pm 15.14 \mathrm{a}$ & $225.23 \pm 20.01 \mathrm{a}$ & $25.76 \pm 2.17 \mathrm{a}$ \\
\hline 1 & $203.62 \pm 18.68 \mathrm{~b}$ & $173.26 \pm 15.28 \mathrm{bc}$ & $27.46 \pm 1.12 \mathrm{a}$ \\
\hline 5 & $146.19 \pm 23.03 \mathrm{bc}$ & $153.17 \pm 7.46 \mathrm{~cd}$ & $28.03 \pm 1.3 \mathrm{a}$ \\
\hline
\end{tabular}

The data are the mean values $(\mathrm{n}=3) \pm$ standard error of the mean; different letters in the same column denote significant differences at $p<0.05$.

counteracting any damage to the $Z$. matrella seedlings due to the allelochemical(s). Under increasing concentrations of extracts the growth of Z. matrella was inhibited as its capacity for photosynthesis and the assimilation of organic matter declined, and these indices were all significantly lower than those of the controls at $80 \mathrm{~g} \mathrm{~L}^{-1}$. A strong inhibitory effect of $A$. philoxeroides extracts on the germination and seedling growth of Parthenium was found in another reported study [27].

Plants form an endogenous antioxidant enzyme protection system to resist adverse conditions, including allelopathic interactions. Reactive oxygen species (ROS) are indispensable messengers during various stages of plant development and stress response [28]. Adverse stresses induce the accumulation of ROS, including $\mathrm{OH}^{-}, \mathrm{H}_{2} \mathrm{O}_{2}$, and $\mathrm{O}_{2}{ }^{-}$in plants, and these ROS may cause oxidative damage to the plant photosynthetic pigments, cell membranes, and proteins, thus leading to the production of membrane lipid peroxidation and increasing MDA content, resulting in serious injury to the plant [29]. To avoid cellular damage by ROS, plants can produce antioxidant enzymes such as superoxide dismutase (SOD) and catalase (CAT) as a defense against the oxidative stress to eliminate the harmful reactive oxygen radicals [30]. The antioxidant enzyme system might scavenge or suppress the active oxygen radicals and thus protect the membranes from peroxidation [31]. Therefore, the activities of SOD, CAT, and the MDA content are usually adopted as important indicators of plants under adverse situations [32]. Our results show that both the SOD and CAT activities of $Z$. matrella increased initially (from 0 to $20 \mathrm{~g} \mathrm{~L}^{-1}$ ) and then declined (from 20 to $80 \mathrm{~g} \mathrm{~L}^{-1}$ ) with increasing concentration of the A. philoxeroides' extracts (Fig. 1), a trend similar to those found in previous studies [33]. Low concentrations of $A$. philoxeroides extracts stimulated the growth of $Z$. matrella and activated the metabolism of antioxidant enzymes (SOD and CAT), thus protecting the growth of $Z$. matrella seedlings from adverse conditions. Nevertheless, when the $Z$. matrella seedlings were subjected to higher concentrations $\left(\geq 40 \mathrm{~g} \mathrm{~L}^{-1}\right)$ of $A$. philoxeroides extracts, abundant allelochemicals in the extracts and the ROS produced in $Z$. matrella destroyed the antioxidant enzymes of $Z$. matrella, and thus the ability of the enzyme systems to scavenge oxygen-free radicals decreased [34]. Therefore, the antioxidant enzymes of $Z$. matrella were insufficient to defend the free radicals, thus resulting in lipid peroxidation and growth inhibition [35]. MDA, a product of membrane lipid peroxidation, is an important index indicating deterioration in cellular metabolism and damage to membrane systems [35]. In the present study the contents of MDA in Z. matrella all steadily increased with increasing concentration of $A$. philoxeroides extracts (Fig. 1). Similar effects were observed in Palmellococcus miniatus incubated in solutions with volatile oil of Artemisia ordosica. The results indicate that the emission of volatile oil of $A$. ordosica increases the MDA content and inhibits photosynthesis through oxidative damage and thus might negatively affect the development of $P$. miniatus [36].

Furthermore, the RI and SE values of Z. matrella suggest that extracts of different plant parts of $A$. philoxeroides had distinct allelopathic activities to inhibit the growth of $Z$. matrella, and the root extracts had the strongest allelopathic effects (Table 2). The extracts of different plant parts of $A$. philoxeroides exerted various allelopathic effects on five vegetable seeds and the allelopathic effect of underground extracts was the strongest in another study.

The question arises as to what is the dominant allelochemical substance leading to the allelopathic phenomenon. Phenolic compounds extracted from different tissues of Sosnowsky's hogweed exerted highly phytotoxic effects on the germination of perennial ryegrass seeds [37]. Extracts of living roots of A. philoxeroides were isolated and identified by GC-MS. According to the mass spectrum of the major peaks and comparison to the NIST mass spectral database, 57, 74, and $102 \mathrm{~m} / \mathrm{z}$ are the characteristic fragmentation ions of ethyl propionate (Fig. 2 ). This does not prove conclusively that ethyl propionate is the sole compound responsible for the allelopathic effect, and this requires further study and verification. Pot experiments were also carried out to study the influence of ethyl propionate on the growth of $Z$. matrella. The results show that the effect of ethyl propionate on the SOD and CAT activities of $Z$. matrella's growth also ranged from slightly stimulatory $(\leq 0.5 \mathrm{mmol})$ to highly 
inhibitory ( $\geq 1 \mathrm{mmol})$ in a similar fashion to the effects of A. philoxeroides extracts on Z. matrella (Table 3 and Table 4). In addition, ethyl propionate was found to have the strongest inhibition of root length in Z. matrella, which accords with the results of Imatomi etal. [38], who found that the order of the inhibitory effect of allelopathic sensitivity (RI) of Codonopsis pilosula followed the sequence root dry weight $>$ root volume $>$ root length $>$ height $>$ seedling dry weight in treatments with high concentrations of ferulic acid (that is, ferulic acid has stronger inhibitory effects on the roots of Codonopsis pilosula than on the aboveground parts). The strongest inhibition of extracts of Solidago canadensis $L$. on the germination of rapeseed was also attributed to the presence of phenolic compounds in all treatments [39]. Moreover, numerous studies show that esters are common allelochemicals. For example, the volatile compounds from Cryptocarya massoy are esters and have been found to have strong allelopathic effects on the growth of Lycopersicon esculentum and Cucumis sativus [40]. Phthalate esters in the root exudates of Welsh onion (including diethyl phthalate and dibutyl phthalate) were found to be the most important allelochemical compounds affecting cucumber. It can therefore be concluded that the ethyl propionate in the root extracts is likely to be the dominant allelochemical substance responsible for the allelopathic activity of $A$. philoxeroides against $Z$. matrella, but further investigation is required to confirm this.

\section{Conclusions}

The allelopathic effects of extracts of each plant part of $A$. philoxeroides on the growth and the antioxidant enzyme activities of $Z$. matrella ranged overall from slightly growth stimulatory to highly growth inhibitory. The strength of the allelopathic effect of the extracts of the three plant parts of $A$. philoxeroides on $Z$. matrella followed the order roots $>$ leaves $>$ stems. The most abundant allelochemical component was identified as ethyl propionate, which exhibited similar inhibition on the growth and enzyme activities of $Z$. matrella. The MDA content was also significantly enhanced with increasing concentration of extracts of $A$. philoxeroides or ethyl propionate. These findings partly explain the mechanisms of biological invasion of $Z$. matrella by $A$. philoxeroides, and also provide information that may aid in the alleviation of the allelopathic effects of $A$. philoxeroides in the field.

\section{Acknowledgments}

We thank the Natural Science Foundation of Anhui Province (No. KJ2012A131 ) and the Foundation of the Provincial Key Laboratory of the Conservation and Exploitation of Biological Resources in Ecological Safety in Anhui Province for financial support.

\section{References}

1. CHAFFIN B.C., GARMESTANI A.S., ANGELER D.G., HERMANN D.L., STOW C.A., NYSTROM M., SENDZIMIR J., HOPTON M.E., KOLASA J., ALLEN C.R. Biological invasions, ecological resilience and adaptive governance. J. Environ. Manage. 9, 2016.

2. GUIVER C., DREIVI H., FILANNINO D.M., HODGSONC D., LLOYDA S., TOWNLEY S. The role of population inertia in predicting the outcome of stage-structured biological invasions. Math Biosci. 265, 11, 2015.

3. CASSEY P., HOGG C.J. Escaping captivity: The biological invasion risk from vertebrate species in zoos. Biol Conserv. 181, 26, 2015.

4. CARDECCIA A., MARCHINI A., OCCHIPINTI A., GALIL B., GOLLASCH S., DAN M., NARSCIUS A., OLENIN S., OJAVEER H. Assessing biological invasions in European seas: Biological traits of the most widespread non-indigenous species. Estuar Coast Shelf S. 23, 12, 2016.

5. GAO L.X., GENG Y.P., YANG H.X., HU Y.H., YANG J. Gene expression reaction norms unravel the molecular and cellular processes underpinning the plastic phenotypes of Alternanthera philoxeroides in contrasting hydrological conditions. Front Plant Sci. 6, 17, 2015.

6. LU X.M., DING J.Q. History of exposure to herbivores increases the compensatory ability of an invasive plant. Biol Invasions. 14, 658, 2012.

7. MEHMOOD A., TANVEER A., NADEEM M.A., ZAHIR Z.A. Comparative allelopathic potential of metabolites of two Alternanthera species against germination and seedling growth of rice. Planta Daninha. 32, 10, 2014.

8. HIERRO J.L., CALLAWAY R.M. Allelopathy and exotic plant invasion. Plant Soil. 256, 39, 2003.

9. HUANG Y., BAI Y., WANG Y., KONG H. Allelopathic effects of the extracts from an invasive species Solidago Canadensis L. on Microcystis aeruginosa. Lett Appl Microbiol. 57, 458, 2013.

10. ZHANG X.X., LIU Z.W., TIAN N., LUC N.T., ZHU B.C., BING Y.H. Allelopathic effects of decomposed leaf litter from intercropped trees on rape. Turk J Agric For. 39, 908, 2015.

11. JIANG Z.Y., GUO P.Y., CHANG C.C., GAO L.L., LI S.X., WAN J.J. Effects of Allelochemicals from Ficus microcarpa on Chlorella pyrenoidosa. Braz Arch Biol Techn. 57, 605, 2014.

12. ALTIKAT S., TERZI I., KURU H.I., KOCACALISKAN I. Allelopathic effects of juglone on growth of cucumber and muskmelon seedlings with respect to antioxidant enzyme activities and lipid peroxidation. J Environ Prot Ecol. 14, 1253, 2013.

13. LI J.M., JIN Z. Potential allelopathic effects of Mikania micrantha on the seed germination and seedling growth of Coix lacryma-jobiwbm. Weed Biol Manag. 10, 201, 2010.

14. ULLAH N., HAQ I.U., SAFDAR N., MIRZA B. Physiological and biochemical mechanisms of allelopathy mediated by the allelochemical extracts of Phytolacca latbenia (Moq.) H. Walter. Toxicol Ind Health. 31, 937, 2015.

15. SIMBERLOFF D., MARTIN J.L., GENOVESI P., MARIS V., WARDEL D.A., ARONSON J., COURCHAMP F., GALIL B., GARCIA B.E., PASCAL M., PYSEK P., SOUSA R., TABACCHI E., VILA M. Impacts of biological invasions: what's what and the way forward. Trends Ecol Evol. 28, 66, 2013. 
16. SACCAGGI D.L., KARSTEN M., ROBERTSON M.P., KUMSCHICK S., SOMERS M.J., WILSON J.R.U., TERBLANCHE J.S. Methods and approaches for the management of arthropod border incursions. Biol Invasions. 18, 1075, 2016.

17. SCHOOLER S.S., COOK T., PRICHARD G., YEATES A.G. Disturbance-mediated competition: The interacting roles of inundation regime and mechanical and herbicidal control in determining native and invasive plant abundance. Biol Invasions. 12, 3298, 2010.

18. HUANG Y.J., ZHOU H., ZHANG D.D., LIU F., CAO Y.H., YANG S.H., ZHOU S.B. Effects of extracts of Alternanthera philoxeroides and rhizospheric soil on growth and physiological characteristics of Zoysia matrella seedlings. J Soil Water Conserv. 29, 291, 2015 [in Chinese]

19. GIANNOPOLITI C.N., RIES S.K. Superoxide dismutases II. Purification and quantitative relationship with watersoluble protein in seedlings. Plant Physiol. 59, 318, 1977.

20. GOTH L. A simple method for determination of serum catalase activity and revision of reference range. Rev Bras Frutic. 196, 151, 1991.

21. HEATH R.L., PACKER L. Photoperoxidation in isolated chloroplasts: I. Kinetics and stoichiometry of fatty acid peroxidation. Arch Biochem Biophys. 125, 198, 1968.

22. WILLIAMSON G.B., RICHARDSON D. Bioassays for allelopathy: treatment responses with independent controls. J Chem Ecol. 14, 187, 1988.

23. SUNMONU T.O., STADEN J.V. Phytotoxicity evaluation of six fast-growing tree species in South Africa. S Afr J Bot. 90, 106, 2014.

24. BHATTACHERJEE A., GHOSH T., SIL R., DATTA A. Isolation and characterisation of methanol-soluble fraction of Alternanthera philoxeroides (Mart.) - evaluation of their antioxidant, $\alpha$-glucosidase inhibitory and antimicrobial activity in in vitro systems. Nat Prod Res. 23, 4, 2014.

25. KIMURA F., SATO M., KATO N.H. Allelopathy of pine litter: delivery of allelopathic substances into forest floor. $\mathrm{J}$ Plant Biol. 58, 67, 2015.

26. SAFDAR M.E., TANVEER A., KHALIQ A., ALL H.H., BURGOS N.R. Exploring herbicidal potential of aqueous extracts of some herbaceous plants against Parthenium weed. Planta Daninha. 34,116, 2016.

27. AHAMD P., SARWAT M., SHARMA S. Reactive oxygen species, antioxidants and signaling in plants. J Plant Biol. 51, 173, 2008.

28. GARCIA A.C., SANTOS L.A., SOUZA L.G., TAVARES O.C., ZONTA E., GOMES E.T., GARCIA J.M., BERBARA R.L. Vermicompost humic acids modulate the accumulation and metabolism of ROS in rice plants. J Plant Physiol. 192, 63, 2016
29. APEL K., HIRT H. Reactive oxygen species: metabolism, oxidative stress and signal transduction. Annu Rev Plant Biol. 55, 749, 2014.

30. YASMEEN A., NOUMAN W., BASRA S.M.A., WAHID A., HAFEEZ U.R., HUSSAIN N., AFZAL I. Morphological and physiological response of tomato (Solanum lycopersicum L.) to natural and synthetic cytokinin sources: a comparative study. Acta Physiol Plant. 36, 3155, 2014.

31. RADWAN D.E.M. Salicylic acid induced alleviation of oxidative stress caused by clethodim in maize (Zea mays L.) leaves. Pestic Biochem Phys. 102, 188, 2012.

32. CANDAN N., TARHAN L. Tolerance or sensitivity responses of Mentha pulegium to osmotic and waterlogging stress in terms of antioxidant defense systems and membrane lipid peroxidation. Environ Exp Bot. 75, 88, 2012.

33. MATTERS G.L., SCANDALIOS J.G. Synthesis of isozymes of superoxide dismutase in maize leaves in response to $\mathrm{O}_{3}$ $\mathrm{SO}_{2}$ and elevated $\mathrm{O}_{2}$. J Exp Bot. 38, 852, 1987.

34. CAI M., LI Y., LI Y., DU K. Physiological and biochemical responses and microscopic structure changes of Populus tomentosa Carr seedlings to 4-BDE exposure. Environ Sci Pollut R. 22, 14268, 2015.

35. KOU X.H., WU M.S., LI L., WANG S., XUE Z.H., LIU B., FEI Y.Q. Effects of $\mathrm{CaCl}_{2}$ dipping and pullulan coating on the development of brown spot on 'Huang guan' pears during cold storage. Postharvest Biol Technol. 99, 72, 2015.

36. YANG X.L., DENG S.Q., PHILIPPIS R.D., CHEN L.Z., HU C.Z., ZHANG W.H. Chemical composition of volatile oil from Artemisia ordosica and its allelopathic effects on desert soil microalgae, Palmellococcus miniatus. Plant Physiol Bioch. 51, 158, 2012.

37. BALEZENTIENE L. Inhibitory effect of invasive Heracleum sosnowskyi on rapeseed and ryegrass germination. Allelopathy J. 30, 208, 2012.

38. IMATOMI M., NOVAES P., MIRANDA F.M., GUALTIERI S.C.J. Phytotoxic effects of aqueous leaf extracts of four Myrtaceae species on three weeds. Acta Sci Agron. 37, 248, 2015.

39. BALEZENTIENE L. Secondary metabolite accumulation and phytotoxicity of invasive species Solidago canadensis L. during the growth period. Allelopathy J. 35 (2), 226, 2015.

40. ROLLI E., MARIESCHI M., MAIETTI S., GUERRINI A., GRANDINI A., SACCHETTI G., BRUNI R. Phytotoxic effects and phytochemical fingerprinting of hydrodistilled oil, enriched fractions, and isolated compounds obtained from Cryptocarya massoy (OKEN) Kosterm. Bark. Chem Biodivers. 13, 76, 2016. 
